\title{
Guest Editorial: The Many Voices of Spanish Bioethics-An Introduction
}

PABLO RODRÍGUEZ DEL POZO and JOSEPH J. FINS

Edmund Pellegrino noted that contemporary medicine is to a large extent a North American product, and so too is the ethics that accompanies it. ${ }^{1}$ This was an accurate observation back in the 1980s when he said it. Even today bioethics is to a considerable extent informed by the seminal works of the Anglo-American model, at least seen from the United States. The dissemination of ideas from the Spanish-speaking world has been nearly invisible to the English-speaking world of bioethics, isolated by language and culture from intellectual currents abroad.

This special issue of Cambridge Quarterly is meant to provide access to the rich scholarship of Spanish bioethics, a distinctive school imbued with a Mediterranean soul and a philosophy that bears the imprint of continental European anthropology along with the influence of North American bioethics through the work of James Drane, David Thomasma, Edmund Pellegrino, ${ }^{2}$ and others.

We believe that a close-up of the latest expressions of this branch of bioethics will bring a number of insights to the English-speaking bioethicist, perhaps the most salient among them being that a highly dynamic, socially responsive bioethics can have a heavy focus on theory and abstraction without compromising its worth as a decisionmaking tool for practitioners and policymakers alike.

First, though, a question. Is there such a thing as a Spanish bioethics?

Diego Gracia Guillén tackles that question in the first article of this collection, in which he analyzes the birth and maturity of bioethics in Spain. As he explains, some in Spain see bioethics as an alien import, whereas others consider it an indigenous development. For Gracia, the truth lies somewhere in between, perhaps leaning closer to the indigenist thesis, which explains the ample social legitimacy that bioethics has achieved in his country. Gracia's personal recounting of his own journey from medicine and philosophy into bioethics synthesizes the intellectual roots of Spanish bioethics. For us, it also shows how much the bioethics of the Spanish-speaking world owes to Gracia's successful effort to synthesize its Mediterranean roots and North American traditions. If a field's opponents are as identity defining as its proponents, Gracia's remarks on how Catholicism and civil law threaten to overtake bioethics only confirm that there is a Spanish bioethics. And it seems to be thriving in a country with more lawyers than France and Germany combined.

Moreover, a secular Spanish bioethics is thriving even though an active minority favors a bioethics that strictly adheres to the Vatican's directives, as seen in Inmaculada de Melo-Martín's piece, "Assisted Reproductive Technology 


\section{Guest Editorial}

in Spain: Considering Women's Interests." De Melo-Martín notes that Spain has one of the world's most liberal policies on assisted reproduction technologies, making these procedures available to all women, married or not, through the national healthcare system. Spanish law, in its most recent iteration of 2003, does not list the procedures allowed, but rather leaves that question open to present and future developments. All that is asked is that they are scientifically validated and used to treat fertility problems. It is permissible to donate gametes and embryos and, under certain safeguards, to carry out research and to perform embryo selection for a sibling's medical treatment that requires a specific genetic makeup. As de Melo-Martín highlights, the law was approved only after a divisive argument framed as a dispute between science and religion. All this is remarkable when it is recalled that contraception was legally banned in Spain until 1978. The current debate has switched from the admissibility of assisted reproductive techniques to how best to protect women's safety, freedom, and autonomy given these technologies.

Somewhat less acrimonious but no less dramatic debates can occur at the bedside in the Spanish-speaking world, where families play a key role in medical decisionmaking, as Juan Pablo Beca and coauthors show in an article from Chile. What should doctors do when the family opposes the deactivation of a cardiac defibrillator that is only prolonging the agony of a terminally ill patient? As Beca et al. suggest, it is normal to have moral reservations, because deactivation can be seen as a way of hastening death. The general absence of living wills or durable power of attorney makes it all the more difficult to know the prior wishes of the patient. Beca and colleagues share their experience from Chilean medical practice and suggest that such moral reservations should be overcome on a case-by-case basis, by understanding the facts. They suggest the utility of educating families and practitioners in some core bioethical notions, such as the idea of futility and the avoidance of disproportionate care in the face of imminent, inevitable, natural death. The authors propose doing this in a culturally competent way, relying on a good understanding of a family's dynamics and belief systems. They stress the need for empathy, with physicians and families reasoning together to achieve the most suitable solution. This may be, in the end, what the Spanish philosopher Adela Cortina proposes, on a much bigger scale, for civic deliberations about bioethics.

In her "Bioethics and Public Reason: A Report on Ethics and Public Discourse in Spain," Cortina maintains that one of the essential roles of bioethics consists of promoting the public use of reason in morally pluralistic societies. Her analysis digs deeply into the nature and extent of moral pluralism, concluding that in pluralistic societies-as opposed to monist ones-there is a common moral ground characterized by an agreement on a strong, but minimal, common ethics. In her view, dilemmas posed by new biomedical developments require defining the specific content of a common minimal bioethics. Because there are no "moral parliaments," Cortina proposes defining, through dialogue, a minimal bioethics that most people recognize as obligatory. The proper context for this dialogue is, for the author, in what she calls "the laboratories of moral judgment," represented by public opinion and bioethics organizations. These laboratories include clinical ethics committees, IRBs, and, above all, national bioethics commissions.

The fifth article of this series discusses one of Cortina's laboratories, namely, the practical experience of the bioethics commission in Puerto Rico. The commission's 
president, psychiatrist Ernesto A. Frontera, reports he had mixed feelings when he was appointed to lead the Puerto Rican Bioethics Advisory Board. On the one hand, he knew it could contribute to shaping the minimal morality the way Adela Cortina defines it, through consensus and dialogue. On the other hand, as he recalls in his article "The Bioethics Advisory Board of Puerto Rico: Personal Reflections on an Initial Agenda," the board ran the risk of being dominated and manipulated by vested interests or monist ideologies. For Frontera, it was important to understand the plurality of interests - to use Cortina's language again-in order to stay equidistant from all of them. It was no less critical to appoint independent, dialogue-minded members who could nevertheless understand these political pressures and deal with them fairly and transparently. Beyond these procedural concerns, the success of this experiment in deliberation depended on defining an agenda that dealt with the priorities of the Puerto Rican healthcare system as perceived by the public so as to gain legitimacy. For Frontera, it is still early to safely state whether the board will be an independent space for reflection or just another bureaucratic entity.

Avoiding bureaucracy and staying connected with people's minimal morality seem to be the recipe for success in what can be seen as another laboratory of moral judgment, the Spanish National Transplant Organization. Spanish lawyer and journalist Carlos Gil-Díaz reports on and analyzes the Spanish law of 1979 on organ transplantation, which established the principle of "presumed consent" (i.e., everyone is presumed to be an organ donor unless he or she convincingly expresses otherwise). Although it would be tempting to link Spain's lead in worldwide organ donor rates to the doctrine of presumed consent, Gil maintains this would be erroneous. In "Spain's Record Organ Donations: Mining Moral Conviction," he attributes this so-called Spanish miracle to the triumph of common ethics over the law, because the organ procurement system relies on moral values and carefully avoids the strict enforcement of the law. Rather, as Gil explains it, the system relies on resources and participation, not to mention efficient organization. Most of all it is considerate of the Spanish mindset, family dynamics, and societally shared values of solidarity.

In some cases, however, ample moral consensus is needed to change a hierarchical penal code, according to Francisco Javier Ansuátegui Roig, who brings the perspective of a Spanish jurist to bear on the problem of euthanasia. In his "Euthanasia, Philosophy, and the Law: A Jurist's View from Madrid," Ansuátegui asserts how, in extreme-but increasingly frequent-circumstances, the natural connection between life and good becomes less than apparent. For him, in those circumstances, the question becomes deontological and person centered with decisions about this linkage returning to the owner of the life under review. Only he or she can determine if the connection exists or not.

For Ansuátegui the problem is that the Spanish legal system makes that connection between life and good a mandatory one, which to a large extent goes against the social grain. In consequence, the author proposes reaching a new social agreement on the public ethics that informs the law. This would translate into a set of rights that would include the right to determine the moment of one's own death, which would be perfectly consistent with the right to autonomy guaranteed, as the author stresses, by the Spanish Constitution of 1978.

Stepping back into the Americas, bioethicists' concerns seem to be focused on human rights and social ethics. Pablo Rodríguez del Pozo and José A. Mainetti 


\section{Guest Editorial}

analyze, in their article "Bioética sin Más: The Past, Present, and Future of a Latin American Bioethics," the birth, development, and future of bioethics in Latin America. The authors recognize the influence of American and, above all, peninsular Spanish bioethics in this process and dissect its components in three stages. The first is dominated by Laín Entralgo's medical anthropology, of great influence in clinical ethics, and the second is focused on human rights, no less influential in clinical ethics, but with an additional focus on public health and broader health policy. The third, a nascent one, is focused on social issues and the profound socioeconomic inequalities prevalent in Latin America and offers contentious proposals based on pursuing total state intervention in all aspects of life to guarantee "collective freedom." The authors propose a bioethics without labels, which deals in an intellectually sound and socially sensitive way with the problems of healthcare, clinical ethics, and justice in the region.

We conclude our collection with the reminiscences and reflections of North American bioethicist James F. Drane, who decades ago initiated linkages between American and Spanish bioethics that we are proud to continue. Drane writes a very personal and insightful account of his intellectual voyage in bioethics and the influences that Spain and Spanish bioethicists have had on his life and career. He emphasizes his Spanish masters and friends and sounds a voice of encouragement for a more transcultural bioethics tying the Anglo-American and Spanish traditions.

We are indebted to all who have contributed to this collection, especially to Michelle A. Wallin for her editorial talents and Thomasine Kushner for her encouragement and support.

\section{Notes}

1. Pellegrino ED. Intersections of Western biomedical ethics and world culture: Problematic and possibility. Cambridge Quarterly of Healthcare Ethics 1992;1(3):191-6.

2. Rodríguez del Pozo P, Fins JJ. Iberian influences on Pan-American bioethics: Bringing Don Quixote to our shores. Cambridge Quarterly of Healthcare Ethics 2006;15(3):225-38. 